\title{
Debate sobre o artigo de Carlos Dimas Martins Ribeiro \& Fermin Roland Schramm
}

\author{
Debate on the paper by Carlos Dimas \\ Martins Ribeiro \& Fermin Roland Schramm
}

\section{Álvaro de Vita}

Faculdade de Filosofia Letras e Ciências Humanas, Universidade de São Paulo, São Paulo, Brasil.

alvaro_vita@uol.com.br

\section{A necessária frugalidade na aplicação de princípios de justiça}

Parece-me extremamente meritório o esforço de Carlos Dimas Ribeiro \& Fermin Roland Schramm de pensar os dilemas das políticas públicas na área da saúde da ótica da concepção de justiça proposta por John Rawls. Um dos problemas que afetam tanto a pesquisa acadêmica sobre as políticas sociais quanto, ao que parece, a própria formulação dessas políticas no Brasil, é o de que essas coisas costumam ser discutidas sem que nenhum vínculo claro seja estabelecido com uma concepção plausível de justiça social. Dito isso, minhas dúvidas e objeções ao artigo de Ribeiro \& Schramm se concentram sobretudo em dois pontos: (1) qual é ou quais são as posições substantivas que os autores se propõem a defender; e (2) a forma pela qual eles conectam essas posições à concepção de Rawls.

No que se refere ao ponto (1), há uma ambigüidade sobre qual é o ponto de vista substantivo que os autores querem defender. Estou denominando "posição substantiva" um ponto de vista sobre quais são ou deveriam ser as prioridades das políticas de saúde com respeito ao problema do envelhecimento progressivo da população. $\mathrm{O}$ argumento substantivo central parece ser o de que, a despeito de haver uma clara tendência de elevação da porcentagem de idosos na população, não há uma justificativa moral aceitável para tornar o prolongamento indefinido da longevidade humana um objetivo prioritário das políticas públicas de saúde. Dada a escassez relativa de recursos, o investimento em tecnologias avançadas e caras, necessário para prolongar a vida de alguns para 100 ou 120 anos, se faria à custa dos investimentos em ações de saúde pública e em " $m e$ dicina paliativa, atenção diária institucional e atenção à saúde domiciliar", que são necessários para assegurar que todos tenham uma oportunidade igual de atingir uma longevidade "normal" (digamos, entre 80 e 90 anos). Além disso, a longevidade não é o único objetivo a ser perseguido. A distribuição de recursos sociais escassos, incluindo os investimentos em ações de saúde, deve ter por objetivo assegurar que, tanto quanto isso seja possível, as oportunidades que cada qual tem de fazer algo de valioso de sua vida caiam dentro de um leque normal de oportunidades ao longo da vida inteira, do nascimento à morte. As instituições $\mathrm{e}$ políticas de saúde devem ter por objetivo propiciar um padrão de "funcionamento normal" para toda a população e ao longo de todos os ciclos vitais do ser humano. Aspirações de atingir uma longevidade de 120 anos, e outras que estão muito além de um padrão de funcionamento normal, podem ser tratadas (apesar de os autores não se valerem dessa noção) como casos de "gostos caros", tais como o gosto por champanhe ou por iates. Aqueles que as cultivam devem também assumir o custo de tentar realizá-las.

Se esse é o argumento sobre a "necessária frugalidade" dos idosos - todos temos de ajustar nossas expectativas, incluindo as que dizem respeito à longevidade, àquilo que razoavelmente podemos esperar de instituições que devem distribuir recursos escassos de forma eqüitativa -, estou inteiramente de acordo com ele. O problema é que esse argumento se combina, de uma forma que não me parece inteiramente clara, com um argumento no sentido de que, dada a escassez de recursos, as políticas públicas de caráter universalista deveriam se combinar com ações e serviços focalizados. Segundo os autores, "numa sociedade eqüitativa, o Estado deveria oferecer uma gama razoável de serviços médicos que seriam priorizados com base numa focalização que consideraria as condições sócio-econômicas dos grupos sociais, conforme estabelece o princípio de diferença, e priorizando os interesses dos cidadãos mais desamparados". Há considerações de dois tipos a fazer sobre essa proposição. A primeira é a de que essa é uma questão distinta da anterior, e os autores estão assumindo com respeito a ela uma posição substantiva que tem conexões pouco claras com o argumento que examinei até aqui. A suposição de que as políticas públicas de saúde devem ter por objetivo restaurar e preservar um certo padrão de funcionamento normal dos cidadãos ao longo de todos os ciclos vitais não equivale, ou não leva de um modo direto, à suposição de que serviços médicos devem ser oferecidos com base em critérios de focalização sócio-econômica. A única coisa em comum entre as duas suposições é a circunstância de escassez de recursos. A segunda consideração é a de que a autoridade do "princípio 
de diferença” da teoria da justiça de John Rawls é invocada para defender o argumento da focalização.

Isso nos leva para o ponto (2) mencionado no primeiro parágrafo. Aqui, minhas discordâncias com os autores são maiores, sobretudo no que se refere à interpretação apropriada do critério de justiça proposto por Rawls. Esse critério tem três componentes distintos: um princípio de liberdades fundamentais iguais, um princípio de igualdade eqüitativa de oportunidades e o "princípio de diferença”, segundo o qual as desigualdades sócio-econômicas (de renda e riqueza, em particular) só são moralmente justificáveis se tiverem por objetivo maximizar os benefícios para o "indivíduo representativo" que ocupa a posição social menos favorável. A interpretação desse critério é complexa 1 . Limito-me, no momento, a fazer alguns breves comentários. Uma primeira observação é a de que as exigências do princípio de diferença não podem ser interpretadas ignorandose os dois outros componentes. Uma maneira simplificada de articular as exigências dos três componentes é dizendo-se algo do seguinte teor: entre os arranjos institucionais que garantem as liberdades fundamentais e uma igualdade eqüitativa de oportunidades, nós deveríamos escolher, para a estrutura básica da nossa sociedade, aqueles que maximizam os benefícios sócio-econômicos (tais como renda e riqueza) para os que vierem a se encontrar na posição social menos favorável. Será um princípio de diferença, que é somente um dos componentes desse critério de justiça, um princípio de focalização? Não vejo por quê. Em que medida a provisão de benefícios focalizados, tais como as formas de renda mínima garantida, contribuem ou não para elevar o quinhão distributivo daqueles que se encontram na posição mínima da sociedade; essa não é uma discussão que possa ser resolvida somente pela aplicação do princípio.

Há um ponto ainda mais importante a ser ressaltado. As implicações de se aplicar diretamente o princípio de diferença para justificar a escolha de políticas de saúde específicas, tais como a provisão focalizada de determinados serviços médicos, podem ser perversas. Os autores têm consciência disso quando afirmam que a concepção de justiça de Rawls se aplica aos arranjos institucionais básicos, "não sendo adequado aplicá-la inteiramente à distribuição de recursos na beira do leito" (penso que a palavra "inteiramente" deveria ser suprimida desta frase). Mas eles parecem se esquecer de qual é o objeto apropriado de aplicação do princípio de diferença quando supõem que esse princí- pio endossa políticas segundo as quais "as tecnologias médicas avançadas (diálise renal, transplante de órgãos, medicina intensiva etc.) podem ser distribuídas com base na focalização, devido a seu alto custo". Confesso o meu desconforto com respeito a essa sugestão. Isso justificaria, por exemplo, que uma pessoa cuja renda seja suficiente para tecnicamente colocá-la na classe média (e que, portanto, não se encontra entre os mais desprivilegiados), mas insuficiente para adquirir um seguro de saúde de boa qualidade, fosse excluída do acesso a esses procedimentos médicos avançados em serviços públicos de saúde? Permitam-me que eu mencione um outro exemplo de aplicação perversa: a justificação da política de "dupla entrada” em hospitais públicos, tais como o Hospital das Clínicas de São Paulo, com base no princípio de diferença, argumentando-se que os benefícios maiores concedidos aos mais privilegiados objetivariam melhorar a qualidade dos serviços para os mais desprivilegiados. Pode até ser que a política de dupla entrada fosse a melhor coisa a fazer, nas circunstâncias, mas seria perverso invocar um princípio de justiça social, como é o caso do princípio de diferença, para justificá-la. O que está faltando em todos esses casos é uma distinção tal como aquela proposta por Jon Elster entre "justiça global” e "justiça local" 2. Princípios de justiça que se aplicam a arranjos institucionais básicos ("justiça global”) podem não ser apropriados para decidir o que é certo fazer em contextos decisórios específicos (“justiça local”), por exemplo, para decidir com base em que critérios se devem distribuir órgãos para transplantes.

O princípio de diferença não é o princípio de justiça com base no qual deveríamos discutir a distribuição de cuidados médicos e de atenção à saúde na sociedade. Essa é minha principal objeção a Ribeiro \& Schramm. O princípio de diferença se aplica aos arranjos institucionais - tais como as normas que regem o direito de propriedade, o sistema tributário e o sistema de transferências - que determinam a distribuição da renda e da riqueza na sociedade. A noção normativa relevante para a discussão de questões de política pública relativas à saúde é a da igualdade eqüitativa de oportunidades. Isso é, aliás, o que faz Norman Daniels quando estende o enfoque de Rawls para dar conta dos casos dos portadores de deficiência e de necessidades médicas especiais (entre os quais podemos incluir as necessidades diferenciadas de cuidados médicos que os idosos têm). Em casos assim, recursos adicionais podem ser necessários para garantir que, tanto quanto isso é possível dadas as limitações impostas pela na- 
tureza, todos tenham oportunidades iguais de atingir um certo padrão "normal" de funcionamento. A questão da focalização é de outra natureza e, no caso da saúde, duvido muito que seja esclarecedor discuti-la com base no princípio de diferença.

1. Vita A. A justiça igualitária e seus críticos. São Paulo: Editora da Unesp; 2000.

2. Elster J. Local justice. How institutions allocate scarce goods and necessary burdens. New York: Russel Sage Foundation; 1992.

Miguel Kottow

Universidad de Chile, Santiago, Chile. guarvie@ctcreuma.cl

\section{Senescencia y protección}

La ética del final de la vida es compleja, no se agota en asignar o reducir recursos sanitarios para la población más provecta. En su seno ha de debatirse el valor que la sociedad otorga a los senescentes, así como la reflexión sobre las diversas formas como la vida humana puede llegar a su término.

Ingresos reducidos, aislamiento social, exclusión familiar, marginación laboral, son todas experiencias que afectan a los individuos senescentes, deficiencias que se hacen más graves a medida que aumenta la población añosa. Las investigaciones biológicas que pretenden prolongar la vida humana y mejorar sus condiciones sanitarias son criticables por profundizar el divorcio existente y persistente entre geriatría (cuidados sanitarios) y gerontología (protección social). La insuficiencia de recursos sanitarios para la tercera edad contrasta con el impacto ya iniciado de una medicina desiderativa que erosiona los límites entre cobertura sanitaria de disfunciones y enfermedad, frente a la mera satisfacción de deseos; el acceso a estos servicios de alto costo sólo será opción para los privilegiados. En esa doble dinámica, de una atención progresivamente deficiente para los ancianos y una medicina interesada en el perfeccionamiento biológico no terapéutico, la ética de la senescencia se debate en una peligrosa involución.

La escasez de recursos sanitarios y el aumento mundial de la proporción de personas mayores, han desencadenado la preocupación de los economistas y la búsqueda de indicadores de eficiencia en la atención médica. Las mediciones de calidad de vida y el desarrollo de estrategias como el TTO (time trade off) en que las personas, o los economistas en su nombre, ponderan inversión de recursos médicos versus expectativas de sobrevida (icuántos años de vida futura sacrificar a cambio de optimizar la atención médica requerida en la actualidad?), buscan criterios de racionamiento que basculan entre los requerimientos de la bioética y las factibilidades de la economía sanitaria 1,2. Similar visión ofrecen las ponderaciones de descuento, en las cuales economistas y bioeticistas como Daniels proponen un ordenamiento social donde las personas deciden cómo distribuir recursos sanitarios a lo largo de la vida, una propuesta demasiado llena de incertidumbres para ser viable. El descuento tiene dos vectores contradictorios: uno que considera razonable ahorrar recursos más dispensables en el presente con miras a necesidades futuras, el otro que privilegia la satisfacción actual porque el futuro es más incierto, de menor valor individual y social, sugiriendo sacrificar años de sobrevida a cambio de una buena cobertura sanitaria en los años más jóvenes. Callahan sugiere restringir servicios médicos terapéuticos, reduciendo las expectativas de vida a los grupos etarios que han cumplido la edad promedio de sobrevida, una política difícil de sostener de forma coherente si las legislaciones y el espíritu cultural prevalente permanecen contrarios a las anticipaciones activas y voluntarias de morir.

Las propuestas de Callahan y Daniels son utilitaristas y pragmáticas, el primero proponiendo un racionamiento de recursos, el segundo proponiendo que, por decisión de tipo rawlsiano (velo de ignorancia), los gastos médicos se redistribuirán ecuánimemente según las necesidades sanitarias a lo largo de cada vida. La similitud conceptual de estas propuestas con lo planteado por la economía sanitaria demuestra que no hay aquí criterios propiamente bioéticos, sino de redistribución utilitaria de recursos.

Ribeiro \& Schramm aptamente contraponen los esquemas de justicia en igualdad frente a la focalización de hecho, en correspondencia con la tradicional distinción entre equidad (recursos iguales para todos) y asimetría (recursos de acuerdo a necesidades), a lo cual cabe agregar que las categorías pueden a su vez ser administrativas (planificación desde arriba) o participativas (prioridades sentadas desde la base). La justicia como máxima moral, inevitablemente debe transformarse en una propuesta de gestión de bienes, pues la distribución es de algo y para alguien. La tipificación se vuelve más difusa en la práctica, pues la justicia en equidad debe transformarse en una pro- 